\title{
Genetic Diversity of the Pythium spp. associated with Root Rot of Chili (Capsicum annum L.) in Pakistan and its Management through Plant extracts
}

\author{
Kiran Nawaz ${ }^{1}$, Ahmad Ali Shahid ${ }^{1,2}$, Waheed Anwar ${ }^{1}$, Sehrish Iftikhar ${ }^{1}$ and Muhammad Nasir \\ Subhani ${ }^{1}$ \\ ${ }^{1}$ Institute of Agricultural Sciences, University of the Punjab, Lahore, Pakistan \\ ${ }^{2}$ Centre of Excellence in Molecualr Biology, University of the Punjab, Lahore, Pakistan
}

\begin{abstract}
Chili (Capsicum annum L.) is an important vegetable crop of Pakistan and affected by root rot disease, is of great significance in different areas of the world. Soil and root samples were collected from different areas of the Punjab, Pakistan. Three different Pythium spp. such as P. intermedium, P. spinosum, and P. aphanidermatum were isolated on specific corn meal agar media. The fungal pathogen was identified on its morphological characters and molecular basis. Internal transcribed spacer region was amplified by using ITS specific primers. Genetic diversity of the Pythium spp. was studied by constructing a neighbor-joining tree. Pythium spp. were classified into three different clades which were clearly distant from each other and all species showed variations. In this study, the efficacy of $1 \%$ aqueous extracts from the leaves of 5 plant species i.e 1\% leaf extracts of Catharanthus roseus, Ocimum sanctum, Ricinus communis, Allium cepa and Allium sativum were screened in vitro by using food poison technique to manage the root rot disease of chili. Plants extracts were evaluated for their antifungal activity over different Pythium spp. All the plant extracts showed the significant reduction in mycelial growth of the pathogen compared with control. Among the different extracts, leaf extract of Allium sativum and Ricinus communis showed promising results to control Pythium spp. Application of plant extracts is cost-effective and eco-friendly method for controlling the plant diseases.
\end{abstract}

Keywords: ITS, Plant extract, Pythium, Root rot

\section{Introduction}

Chili (Capsicum annum L.), member of Solanaceae family is a spice and vegetable crop of substantial economic importance in Pakistan [1]. Chili is a very essential vegetable ranked after tomato and potato. Among the vegetable grown in Pakistan, chili is an important cash crop all over the world. Chili is affected by a number of plant pathogens including fungi which cause root and crown rot [2]. These pathogenic fungi are recorded in almost all chili growing areas of the world. Various plant pathogenic fungi are responsible for root rot disease of chili in Pakistan. The casual pathogens of root rot include Fusarium species mostly cause wilting and rotting of plants. Whereas, Leveillula taurica is responsible for powdery mildew and Pythium aphanidermatum mostly caused wilt, damping off and root rot of chili seedling [2]. Pythium root rot, occasionally called damping off and wilt might be caused by different Pythium species in the world [3]. There has been an immense bang of using various fungicides all over the world after the end of the Second World War. Due to major acceptable fear in near the beginning of $60 \mathrm{~s}$ because of the hazardous results to environment and human health in this green revolution area [4], there has been a vital necessitate for substitute technique to manage the plant disease. This situation needs the exploration and the development of ecologically sustainable fungal management measures that are efficient to various target pathogens and produce minimum harm to non-target pathogens. Plant extracts can be used as an alternative to pesticides and historical success has been found by using azadirachtin, alakloids, 
terpenoids and flavorniods from the aloe plant, ginger, garlic and onion to use as important fungicides and biopesticides. Various concentrations of cold water extracts of Garcinia cola (bitter kola), Allium indica (neem), and Zingiber officinale (ginger) have antifungal activity against vegetative and reproductive growth of soil fungus such as Pythium, Fusarium, Rhizoctonia and Sclerotium rolfsii studied by Wokocha and Okereke [5]. Alternative control measures are necessary due to certain troubles related with chemical control strategies. The purpose of this study is to give practical information on reasonable, cheaper, innate and environmentally friendly pesticide in the management of root rot disease of Pythium species.

\section{Material and methods}

\subsection{Isolation of Pathogens}

The infected plants with root and soil samples were collected from chili growing areas of the Punjab, Pakistan. These roots and soil samples were placed in Petri dishes after surface sterilization by $1 \% \mathrm{NaClO}$ for 1 min. Pathogen was isolated on corn meal agar (CMA) media supplemented with pimaricin $\left(10 \mathrm{mgL}^{-1}\right)$, ampicillin $\left(250 \mathrm{mgL}^{-1}\right)$, rifampicin $\left(10 \mathrm{mgL}^{-1}\right)$ and plates were incubated at $22^{\circ} \mathrm{C}$ in the dark.

\subsection{Morphological identification of fungi}

Isolated fungi were identified using the standard manuals or references including Barnett and Hunter [6], Nelson et al. [7].

\subsection{Molecular identification of fungi}

\subsubsection{Isolation of fungal genomic DNA}

Total genomic DNA of Pythium species was isolated from 1 gram fresh mycelium by using modified method of Schafer and Wostemeyer [8] with slight modifications. DNA concentration was estimated by $0.8 \%$ (w/v) agarose gels and staining was done with ethidium bromide.

\subsubsection{Amplification of ITS region}

Internal transcribed spacer region of fungus was amplified by using ITS1 and ITS4 primers described by White et al. [9]. PCR thermo cycler was run by using the following PCR conditions: denaturation was done at 94 ${ }^{\circ} \mathrm{C}$ for $1 \mathrm{~min}$ and $50{ }^{\circ} \mathrm{C}$ annealing temperature was used for 1 minute. Extension temperature was $72{ }^{\circ} \mathrm{C}$ for 1 $\min 30 \mathrm{~s}$ and final extension was carried out at $72{ }^{\circ} \mathrm{C}$ for $7 \mathrm{~min}$ and 40 cycles were used.

\subsubsection{Sequencing, identification and phylogenetic analysis}

Amplified PCR products of $950 \mathrm{bp}$ were sent for sequencing and ITS sequences of Pythium spp were compared with already reported sequences of Pythium species in the National Centre for Biotechnology Information database (NCBI) by BLAST search (http://blast.ncbi.nlm.nih.gov/blast.cgi). Phylogenetic analysis was performed by using MEGA 6 software [10].

\subsection{Pathogenicity test}

The pathogenicity tests of Pythium spp. were carried out at the Institute of Agricultural Sciences, University of the Punjab, and Lahore, Pakistan in the greenhouse. Colonization and infection \% were recorded after every five days. The spore suspension containing 100 spores $\mathrm{mL}^{-1}$ were prepared and inoculated in pots.

\subsection{Preparation of plant extracts}

The local plants; Catharanthus roseus, Ocimum sanctum, Ricinus communis, Allium cepa and Allium sativum used in this study were collected from vegetable gardens and market around Lahore. Three concentrations of each test plant extracts, i.e. $(1 \%, 2 \%, 4 \%)$ were used. Plant extracts were prepared by taking plant parts and macerated with mortar and pestle in distilled water. Grinding powder was kept overnight in culture tubes for the exudation of bio-chemicals at $4{ }^{\circ} \mathrm{C}$ and filtered using muslin cloth. The filtrate was subjected to centrifugation at $10,000 \mathrm{rpm}$ for $5 \mathrm{~min}$ and the supernatant was sterilized and stored at $4{ }^{\circ} \mathrm{C}$ as stock solutions. 


\subsection{Antifungal activity assay of botanical extracts by using poison food technique}

Antifungal activity of plant extracts was determined by using poisoned food technique [11]. Fungal culture of five day old was punched aseptically by using sterile cork borer with $7 \mathrm{~mm}$ in diameter. Punctured fungal mycelium discs were placed on agar plate. Plant extracts with three different concentrations of 1,2 , and $4 \%$ were poured into agar plates at $45-50{ }^{\circ} \mathrm{C}$ temperature and agar plates were incubated at $22 \pm 1{ }^{\circ} \mathrm{C}$ for the growth of Pythium spp. Percentage inhibition of fungal mycelium growth was determined by comparing the colony diameter of poisoned plate (with plant extract) and non-poisoned plate (with distilled water) and calculated using the formula given below [12].

$\%$ Mycelial inhibition $=$ Mycelial growth $_{(\text {control) }}-$ Mycelial growth $_{\text {(treatment) }}$ X 100/ Mycelia growth (control)

\section{Results and Discussion}

\subsection{Morphological characterization of fungi associated with root rot of chili}

Total three fungal species such as Pythium spinosum, Pythium intermedium, and Pythium aphanidermatum associated with root rot of chili were isolated on CMA media. Morphological characterizations of Pythium spp. were recorded by studying the micro and macro characteristics which include vegetative growth and structure, reproductive structures, sporangia, colony color and conidia. Morphological characters of Pythium species are given in the figure 1.

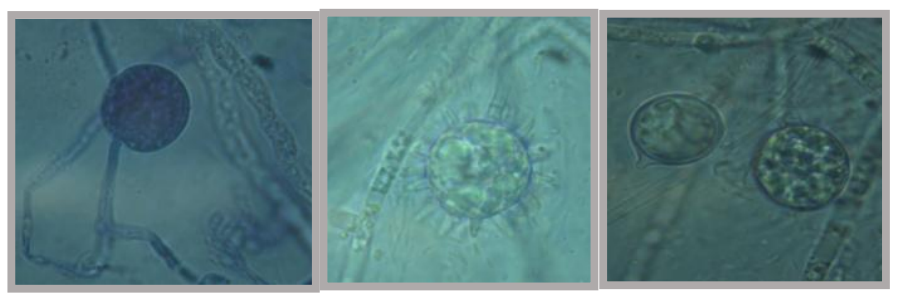

Fig. 1: Morphological characterization of Pythium spp. a: Globose sporangia b: spiny sporangia c: antheridia and oogonia $(100 x)$

\subsection{Molecular characterization of fungi associated with root rot of chili}

Three Pythium species; P. aphanidermatum, P. spinosum, and P. intermedium which were the most widely distributed species were identified on the basis of ITS region of rDNA sequences. Amplified product was purified, sequenced and submitted to NCBI (National Center for Biotechnology Information) database with GenBank no LN867319 P. spinosum, LN890578 P. intermedium, LN890579 P. aphanidermatum. BLAST analysis showed the 100-99\% percentage similarities of different Pythium species with already reported species in the database. Thus, the species name was assigned on the basis to the closest BLAST search.
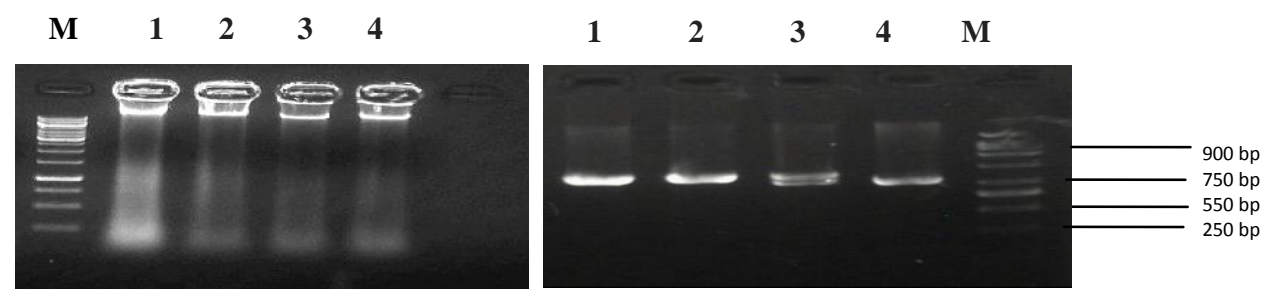

Fig. 2: Gel electrophoresis of genomic DNA isolated from fungi and PCR amplification of ITS region of fungal isolates with ITS1 and ITS4 primers directed the amplification of an approximately $900 \mathrm{bp}$ rDNA fragment from all isolates. $P$. aphanidermatum, $P$. spinosum, and $P$. Intermedium $(1,2,3)$ respectively and $\mathrm{M}=$ Promega $1 \mathrm{~Kb}$ DNA ladder.

\subsection{Pathogenicity test}

Inoculated plants showed the symptoms of wilting and stem lesions similar to those were observed in naturally infected plants after 15 days. Control plants remained healthy and showed no symptoms. The pathogen was re-isolated and confirmed morphologically. Root rot diseases that were caused by different Pythium species have already been reported on many plant species worldwide [13]. 


\subsection{Phylogenetic analysis of Pythium species}

A neighbour-joining phylogenetic tree was constructed based on the already reported 5.8S rDNA gene sequences in database to study the genetic diversity between various species of Pythium. Isolated fungal species were divided into three different clades consisting the Pythium species. In the phylogenetic tree, the P. spinosum (LN867319) showed maximum similarities with $100 \%$ bootstrap value of $P$. spinosum (KU205227) (Figure 3 ). Whereas, the $P$. intermedium (LN890578) was found into a distinctive clade that was evidently different from the other species of Pythium in the neighbor-joining tree and showed maximum homology with $97 \%$ bootstrap value of $P$. intermedium (KU211451). P. aphanidermatum (LN890579) was classify into the distant clade and showed maximum closeness with $P$. aphanidermatum (KU211251). A relative analysis of 5.8S rDNA gene sequence shown that our fungal species are very similar to already reported member of the genus. The phylogenetic studied showed that by using species-specific primers of 5.8S rDNA sequences, genetic diversity and similarities achieved from the alignment analysis of the ITS sequenced. Specific proportional results of the nucleotide sequences of rDNA genes give a potential method to analyze phylogenetic relationships within a broad array of taxonomic specie levels both in non-fungal groups and fungal [14].

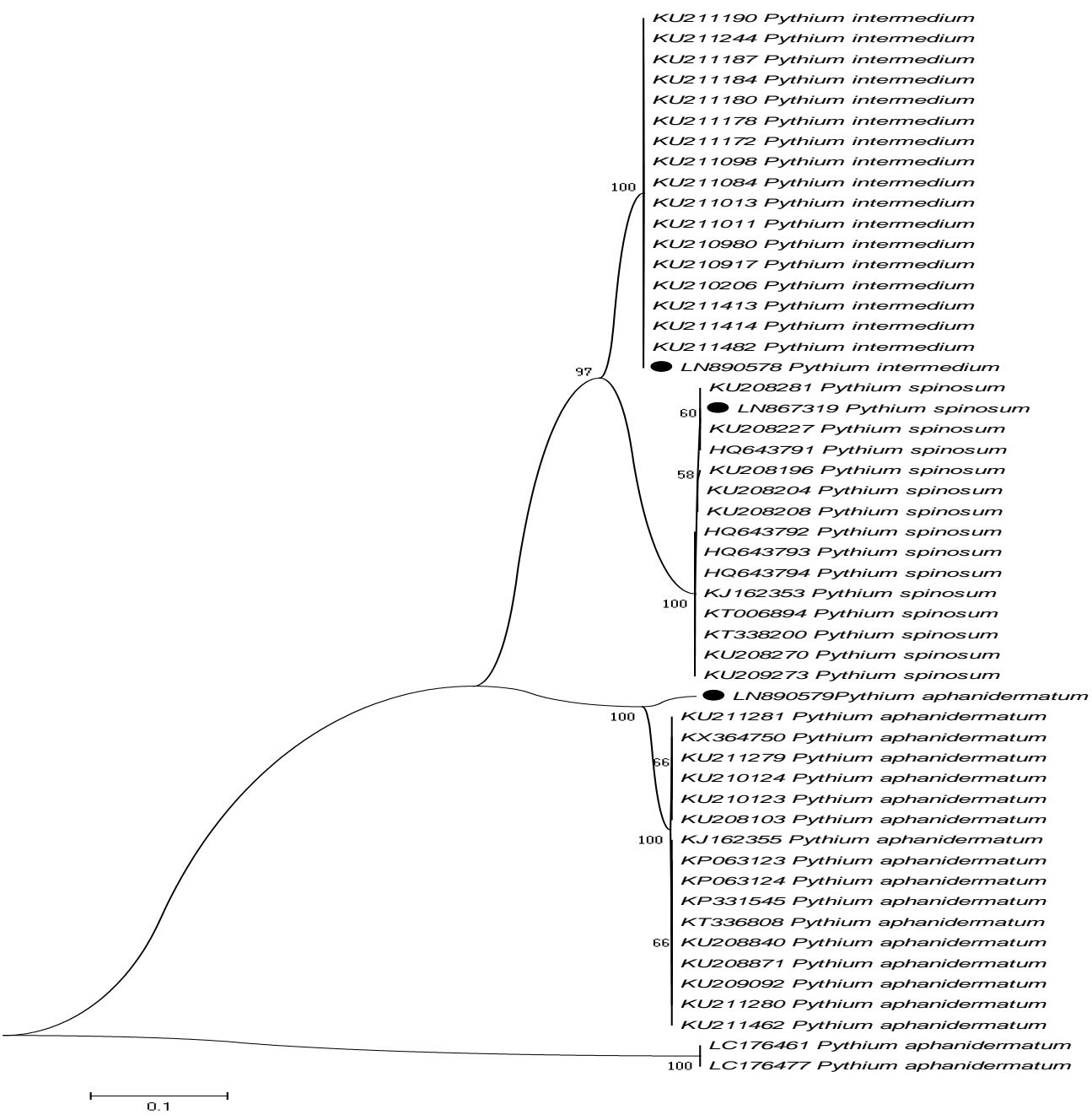

Fig. 3: Evolutionary phylogenetic relationship of Pythium spp. on the basis of ITS rDNA sequences aligned by ClustaIW and was constructed by neighbourhood -joining tree.

\subsection{Antifungal activity assay of botanical extracts by using poison food technique}

The efficiency of a variety of plant extracts were evaluated in vitro on Pythium species causing root rot of chili. The extract of $A$. Sativum and $R$. communis were very effective with the highest inhibiting fungal 
mycelium growth and insufficient sclerotial formation with concentration of $4 \%$. Whereas the slightest growth inhibition was measured in $C$. roseus, $A$. Cepa, and $O$. Sanctum leaf extracts. The results presented in figure 4 showed that most of the plant extracts decreased the fungal growth as compared to control. The present findings showed that greatest growth inhibition was recorded in Allium sativum directly followed by Allium cepa, whereas $O$. sanctum extracts were fairly efficient to reduce the fungal growth at $4 \%$ concentrations. Similar result was also recorded by Dhingani et al. [15]. Similarly, Muzammil et al. [16] and Meena et al. [17] evaluated that $A$. sativum also inhibited mycelium growth of $M$. phaseolina of sunflower. Dubey and Dwivedi [18] reported that $M$. phaseolina vegetative growth such as mycelium and sclerotial viability was reduced with toxic properties of A. Sativum, Acacia arabica, and Allium cepa. Sindhan et al. [19] reported that Rhizoctonia solani and $R$. bataticola causing root rot of chickpea, and bhindi were more sensitive to extracts of A. cepa, A. sativum, Zingiber officinale. Thus, the present findings are in confirmation with the work of above research workers.
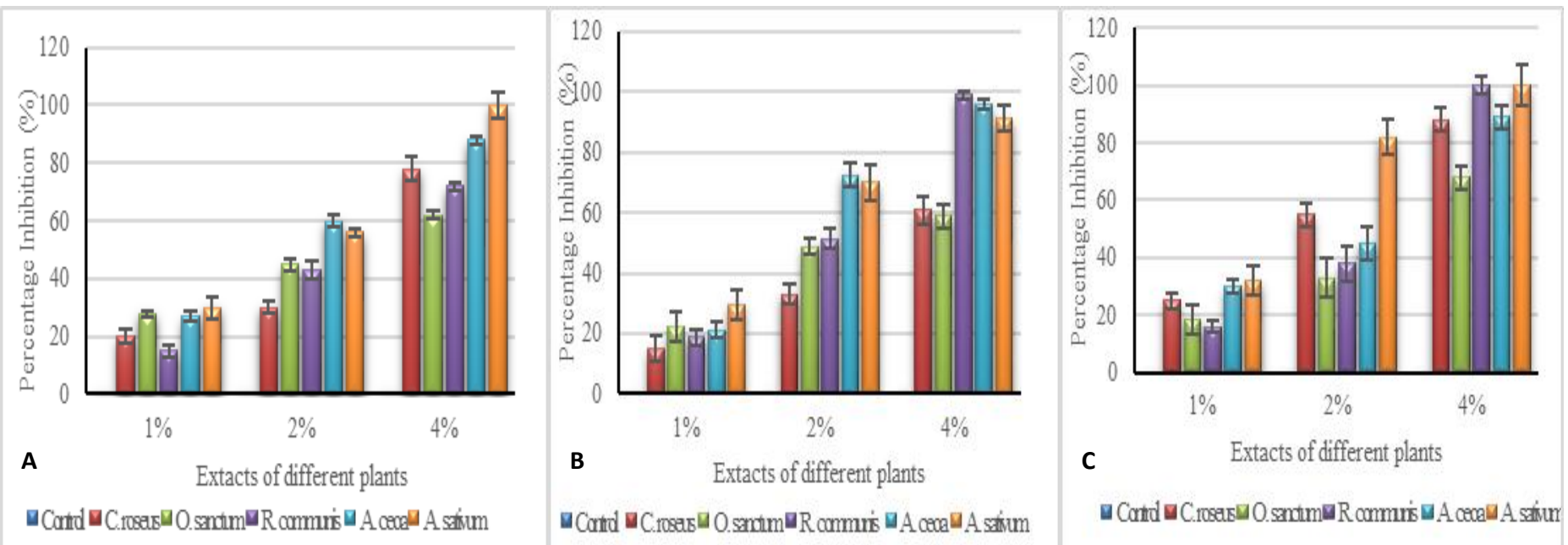

Fig. 4: Antimicrobial inhibition zone diameters $(\mathrm{mm})$ of aqueous combination of plant extract on the radial growth of fungi $P$. intermedium (A), P. spinosum (B), and P. aphanidermatum (C) in vitro.

\section{Conclusion}

The significant genetic differences were found between Pythium species and the capability of outcross will consent to quantitative genetic approaches to recognise pathogenicity determinants in Pythium spp. The study demonstrated that the five plant extracts had antifungal activity against Pythium spp. Allium sativum and Ricinus communis showed highest antifungal activity on all different fungal species and demonstrating that it had better promise as a potential antifungal agent. This confident the use of plant extracts for controlling fungal infections. Further this extract can be effectively incorporated in different forms for the control of these fungi in the field condition.

\section{References}

[1] Khan, Zehra, et al. "Effects of $\mathrm{N}$ fertilisation, organic matter, and biofertilisers on the growth and yield of chilli in relation to management of plant-parasitic nematodes. Turk J Bot, vol. 36(1), pp. 73-81, 2012.

[2] Hussain, Faisal, and Muhammad Abid. "Pest and diseases of chilli crop in Pakistan: A review." Int. J. Biol. Biotech, vol. 8(2), pp. 325-332, 2011.

[3] Agrios, George N. Plant pathology. vol. 5. Burlington, MA: Elsevier Academic Press, 2005.

[4] O'hare, G. P., and P. Williams. "Some effects of sulphur dioxide flow on lichens." The Lichenologist, vol. 7(2), pp. 116$120,1975$. https://doi.org/10.1017/S0024282975000163

[5] Enyiukwu, D. N., et al. "Significance of characterization of secondary metabolites from extracts of higher plants in plant disease management." Int J Adv Agric Res, vol. 2, pp. 8-28, 2014. 
[6] Barnett, Horace Leslie, and Barry B. Hunter. "Illustrated genera of imperfect fungi." pp. 930-932, 1972.

[7] Nelson, P.E., T.A. Toussoun and W.F.O. Marasas. 1983. Fusarium Species: an Illustred Manual for Identification. No. 632.4/N428. The Pennsylvania State University, 1983.

[8] Schafer, C., and J. Wostemeyer. "Random Primer Dependent PCR Differentiates Aggressive from Non-Aggressive Isolates of the Oilseed Rape Pathogen Phoma lingam (Leptosphaeria maculans)." J Phytopatholo, vol. 136(2), pp. 124136, 1992. https://doi.org/10.1111/j.1439-0434.1992.tb01290.x

[9] White, Thomas J., et al. "Amplification and direct sequencing of fungal ribosomal RNA genes for phylogenetics." PCR protocols: a guide to methods and applications, vol. 18(1), pp. 315-322, 1990.

[10] Tamura, Koichiro, et al. "MEGA6: molecular evolutionary genetics analysis version 6.0." Mol Biol Evol, vol. 30 (12), pp. 2725-2729, 2013. https://doi.org/10.1093/molbev/mst197

[11] Nene, Y. L., and P. N. Thapliyal. "Poisoned Food Technique." Fungicides in Plant Disease Control, 2000.

[12] Das, K., R. K. S. Tiwari, and D. K. Shrivastava. "Techniques for evaluation of medicinal plant products as antimicrobial agents: Current methods and future trends." J. Med. Plants, vol. 4(2), pp. 104-111, 2010.

[13] Saleem, A., Bokhari, M. H., Hamad, K., and Ansar, M. Mycoflora associated with root and collar rot disease of chilies in different districts of the Punjab. Pakistan J Bot, vol. 9, pp. 80-84, 1996.

[14] Kumar, C. Prasanna, et al. "Efficiency of universal barcode gene (Coxi) on morphologically cryptic mugilidae fishes delineation." Trends Appl Sci Res, vol. 6(9), pp. 1028, 2011. https://doi.org/10.3923/tasr.2011.1028.1036

[15] Dhingani, J. C., Solanky, K. U. and S. S. Kansara. "Management of root rot disease [Macrophomina phaseolina (Tassi.) Goid] of chickpea through botanicals and oil cakes." The Bioscan, vol. 8(3), pp. 739-742, 2013.

[16] Muzammil, H., et al. "In vitro evaluation of fungicides and plant extracts for suppressing mycelium growth of Macrophomina phaseolina causes charcoal rot of sunflower." Int J Agr Sci, vol. 6(2), pp. 136-140, 2014.

[17] Meena, P. N., et al. "Bio-efficacy of phytoextracts and oil cakes on Macrophomina phaseolina (Tassi) causing stem rot disease of jute, Corchorus spp." J. Appl. Nat. Sci, vol. 6(2), pp. 530-533, 2014. 530533.

[18] Dubey, R. C., and R. S. Dwivedi. "Fungitoxic properties of some plant extracts against vegetative growth and sclerotial viability of Macrophomina phaseolina." Indian phytopathol, vol. 44(3), pp. 411-413, 1991.

[19] Sandipan, Prashant B. "Bioefficacy of water based phytoextracts against dry rot and charcoal rot pathogens of potato caused by Fusarium sp. and Macrophomina phaseolina under in vitro test condition." Int. j. life sci. biotechnol. pharma res, vol. 3 , pp. 69, 2014. 